Research Paper

\title{
High uric acid (UA) downregulates bone alkaline phosphatase (BALP) expression through inhibition of its promoter activity
}

\author{
Zhi-Qi Wu ${ }^{1, *}$, Xiao-Ting Chen ${ }^{1, *}$, Yan-Yan Xu' ${ }^{2, *}$, Ming-Jie Tian ${ }^{1}$, Hai-Yan Chen ${ }^{1}$, Guo- \\ Ping Zhou ${ }^{2}$ and Hua-Guo $\mathrm{Xu}^{1}$ \\ ${ }^{1}$ Department of Laboratory Medicine, The First Affiliated Hospital, Nanjing Medical University, Nanjing, Jiangsu Province \\ 210029, China \\ ${ }^{2}$ Department of Pediatrics, The First Affiliated Hospital, Nanjing Medical University, Nanjing, Jiangsu Province 210029, China \\ *These authors contributed equally to this work
}

Correspondence to: Hua-Guo Xu, email: huaguoxu@njmu.edu.cn

Keywords: bone alkaline phosphatase, uric acid, promoter, bone metastasis

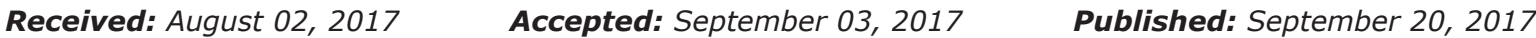

Copyright: Wu et al. This is an open-access article distributed under the terms of the Creative Commons Attribution License 3.0 (CC BY 3.0), which permits unrestricted use, distribution, and reproduction in any medium, provided the original author and source are credited.

\begin{abstract}
Bone metastases often occur in prostate cancers, lung cancers and breast cancers. Bone alkaline phosphatase (BALP) is one of the most commonly used serological markers for clinical evaluation of bone metabolism. Here, we reported that high concentrations of uric acid (UA) caused decrease of BALP levels and revealed that the effect of high concentrations of UA on the BALP expression was through inhibition of its promoter activity. Our results suggested physicians to think about serum UA status of patients with advanced cancer to avoid misdiagnosis when BALP was used to diagnose or assess the extent of bone metastases.
\end{abstract}

\section{INTRODUCTION}

Tumor metastasis is a leading cause of death in patients with advanced cancer [1-3]. Bone is the common site for metastasis in tumor $[4,5]$. Bone metastases often occur in prostate cancers, lung cancers and breast cancers [6-12]. Early detection and accurate description of extent of metastatic bone disease is of great significance to the improvement of the quality of life and of the survival time of patients with advanced cancer [13-16]. Bone scintigraphy, the gold standard for monitoring metastatic bone involvement, is highly sensitive in the diagnosis of bone metastases [17-21]. However, it lacks specificity and is not suitable for the patients follow up [22, 23]. In contrast, serological detection has the advantages of early diagnosis, rapid detection and easy continuous monitoring [24-27].

The serological markers of bone metabolism mainly consist of bone formation and resorption markers, such as the bone formation markers tALP, BALP, $\mathrm{OC}$ and P1NP and the bone resorption markers BSP, NTX, CTX and TRACP 5b [28-37]. Bone ALP is an $80-\mathrm{kDa}$ glycoprotein, which was found on the surface of osteoblasts. Concentration of BALP generally reflects the rate of bone formation in skeletal tissue [28]. Previously, we reported that the patients with high concentrations of uric acid (UA) presented a false-negative decrease in tartrate-resistant acid phosphatase (TRACP) 5b, a marker of bone resorption, due to a method-related systematic error [38]. It suggested physicians to fully consider interference of hyperuricemia, when TRACP $5 \mathrm{~b}$ was used for early diagnosis of cancer patients with bone metastasis, evaluation of the aggressiveness of osteosarcoma or prediction of survival in prostate cancer and breast cancer with bone metastases [38]. Considering that BALP is one of the most commonly used serological markers for clinical evaluation of bone metabolism [28-29], we here elucidated the effect of high concentrations of UA exposure on bone metabolism indicator BALP and further revealed its mechanism.

\section{RESULTS}

Negative correlation between the serum concentrations of UA and BALP

Previously, we have reported that high concentrations of UA led to decreased tartrate-resistant acid phosphatase 5b, a marker of bone resorption, in the general population [38]. Here, we checked if BALP, one of the most commonly used serological markers for 
clinical evaluation of bone metabolism, was affected by high concentrations of UA or not. We randomly tested the BALP levels of 91 high-UA individuals (UA concentration: $485.58 \pm 60.39 \mathrm{IU} / \mathrm{ml}$ ) and 91 healthy subjects (UA concentration: $275.40 \pm 64.15 \mathrm{IU} / \mathrm{ml}$ ). The results showed that the average BALP levels of the highUA individuals $(13.07 \pm 3.69 \mu \mathrm{g} / \mathrm{L})$ were significantly lower $(t$-test, $p$ value $<0.0001)$ than the healthy subjects $(16.13 \pm 4.87 \mu \mathrm{g} / \mathrm{L})$ (Table 1) (Figure 1A). The results also indicated that high concentrations of UA led to decreased of BALP levels was not related to sex (Figure 1B, 1C).

\section{Partial removal of UA in vivo through renal dialysis led to increase of BALP levels}

To confirm whether high UA concentrations lead to decrease of BALP levels, we tested the BALP levels of 3 dialysis patients 10 minutes before and 10 minutes after renal dialysis. UA concentrations of these 3 patients after renal dialysis decreased from 342 to $53 \mu \mathrm{M}, 493$ to $208 \mu \mathrm{M}$, and 498 to $202 \mu \mathrm{M}$, respectively (Figure 2A). In contrast, the levels of their BALP increased from 11.8 to $15.5 \mu \mathrm{g} / \mathrm{L}, 9.4$ to $12.2 \mu \mathrm{g} / \mathrm{L}$, and 9.0 to $11.2 \mu \mathrm{g} / \mathrm{L}$, respectively (Figure $2 \mathrm{~B}$ ). In addition, the concentrations

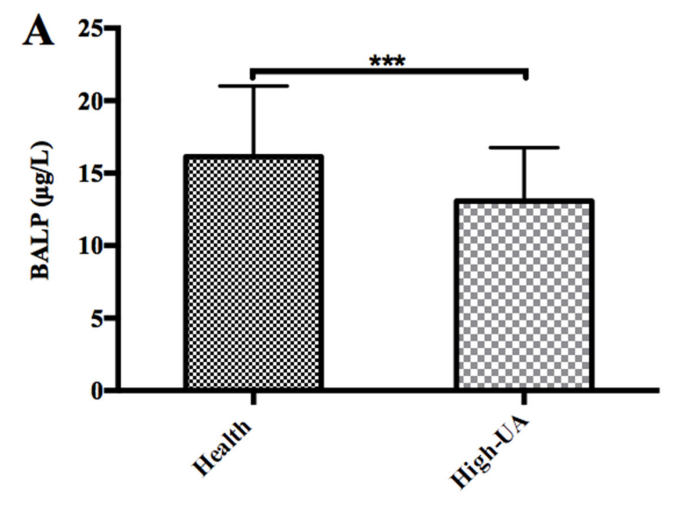

of UA and BALP of No. 1 patient among these 3 patients were detected 10 minutes before, half the time of and 10 minutes after renal dialysis. His results showed negative correlation between the concentrations of UA and BALP during hemodialysis $(\mathrm{R}=-0.995)$ (Figure $2 \mathrm{C}$ ). These data suggested that decrease of UA concentrations led to increase of BALP levels.

Based on the above data, we demonstrated that there was a negative correlation between UA concentrations and BALP levels in general population.

\section{High concentrations of UA did not interfere with BALP immunoassay}

Since high UA concentrations can falsely decrease TRACP 5b levels due to a method-related systematic error, we examined whether high UA concentrations interfered with BALP immunoassay. We performed interference experiments according to the procedure we have described in "Materials and Methods". We spiked serial dilutions of UA into BALP standard samples and a serum sample from one patient with confirmed bone metastasis, respectively. As a result, we did not observe that BALP levels were affected by gradually increasing doses of UA

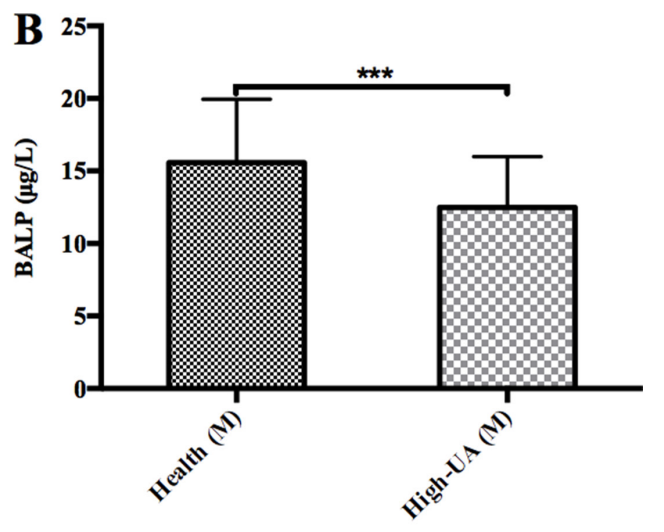

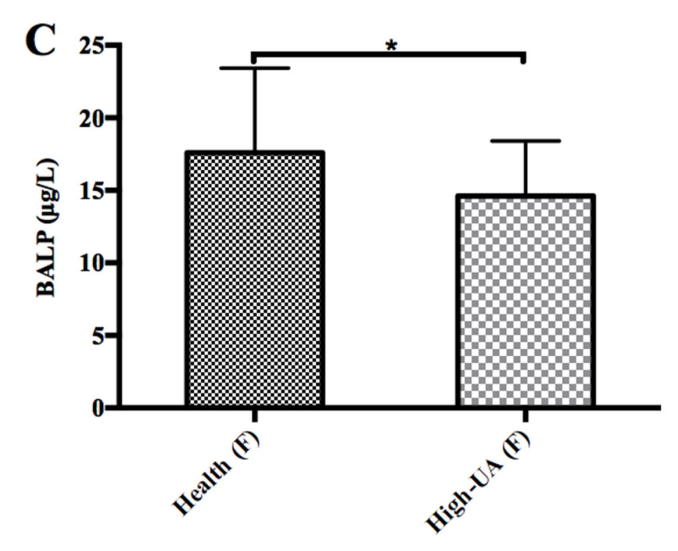

Figure 1: The levels of BALP in the high uric acid groups were significantly lower than the control groups. (A) The average BALP levels of the 91 high-UA individuals $(13.07 \pm 3.69 \mu \mathrm{g} / \mathrm{L})$ were significantly lower $(t$-test, $p$ value $<0.0001)$ than the 91 healthy subjects $(16.13 \pm 4.87 \mu \mathrm{g} / \mathrm{L})$. (B) The average BALP levels of the 66 male high-UA individuals $(12.48 \pm 3.50 \mu \mathrm{g} / \mathrm{L})$ were significantly lower ( $t$-test, $p$ value $<0.0001)$ than the 66 male healthy subjects $(15.57 \pm 4.38 \mu \mathrm{g} / \mathrm{L})$. Triple asterisk indicates $p$ value $<0.0001$, and an asterisk indicates $p$ value $<0.05$. (C) The average BALP levels of the 25 female high-UA individuals $(14.62 \pm 3.78 \mu \mathrm{g} / \mathrm{L})$ were significantly lower $(t$-test, $p$ value $<0.05)$ than the 25 female healthy subjects $(17.59 \pm 5.83 \mu \mathrm{g} / \mathrm{L})$. 
Table 1: Multiple parameters of serum sample and statistical analyses between groups

\begin{tabular}{|c|c|c|c|}
\hline Parameter & Study group & Control group & $P$ value \\
\hline Number of patient (n) & 91 & 91 & l \\
\hline Gender (male/female) & $66 / 25$ & $66 / 25$ & / \\
\hline Age (years, mean \pm SD) & $41.48 \pm 16.25$ & $42.78 \pm 14.69$ & 0.573 \\
\hline WBC $\left(* 10^{9} / \mathrm{L}\right.$, mean \pm SD $)$ & $6.85 \pm 1.29$ & $5.95 \pm 1.29$ & $0.000 * * *$ \\
\hline NEU \% $($ mean \pm SD $)$ & $56.37 \pm 8.08$ & $55.28 \pm 7.02$ & 0.332 \\
\hline $\operatorname{ALT}(\mathrm{U} / \mathrm{L}$, mean $\pm \mathrm{SD})$ & $26.41 \pm 10.13$ & $20.01 \pm 9.21$ & $0.000 * * *$ \\
\hline $\operatorname{AST}(\mathrm{U} / \mathrm{L}$, mean $\pm \mathrm{SD})$ & $22.41 \pm 5.29$ & $22.82 \pm 5.60$ & 0.611 \\
\hline $\operatorname{AFP}(\mathrm{ng} / \mathrm{ml}$, mean $\pm \mathrm{SD})$ & $2.93 \pm 1.37$ & $3.41 \pm 5.79$ & 0.442 \\
\hline CEA $(\mathrm{ng} / \mathrm{ml}$, mean $\pm \mathrm{SD})$ & $1.90 \pm 1.01$ & $1.84 \pm 0.83$ & 0.642 \\
\hline Glu $(\mathrm{mmol} / \mathrm{L}$, mean $\pm \mathrm{SD})$ & $5.24 \pm 4.67$ & $5.02 \pm 4.31$ & $0.001 * *$ \\
\hline BUN $(\mathrm{mmol} / \mathrm{L}$, mean \pm SD) & $5.31 \pm 1.03$ & $5.08 \pm 1.14$ & 0.158 \\
\hline $\operatorname{CREA}(\mu \mathrm{mol} / \mathrm{L}$, mean $\pm \mathrm{SD})$ & $76.39 \pm 15.69$ & $75.06 \pm 14.02$ & 0.548 \\
\hline $\mathrm{UA}(\mu \mathrm{mol} / \mathrm{L}$, mean $\pm \mathrm{SD})$ & $485.58 \pm 60.39$ & $275.40 \pm 64.15$ & $0.000 * * *$ \\
\hline $\mathbf{B A L P}(\mu \mathrm{g} / \mathrm{L}$, mean $\pm \mathrm{SD})$ & $13.07 \pm 3.69$ & $16.13 \pm 4.87$ & $0.000 * * *$ \\
\hline
\end{tabular}

WBC refers to white blood cells, NEU refers to neutrophils, ALT refers to alanine aminotransferase, AST refers to aspartate aminotransferase, AFP refers to alpha fetoprotein, CEA refers to carcinoembryonic antigen, Glu refers to blood glucose, BUN refers to blood urea nitrogen, CREA refers to creatinine, UA refers to uric acid and BALP refers to bone-specific alkaline phosphatase (“**” indicates $p$ value $<0.01$, “***” indicates $p$ value $<0.001$ ).
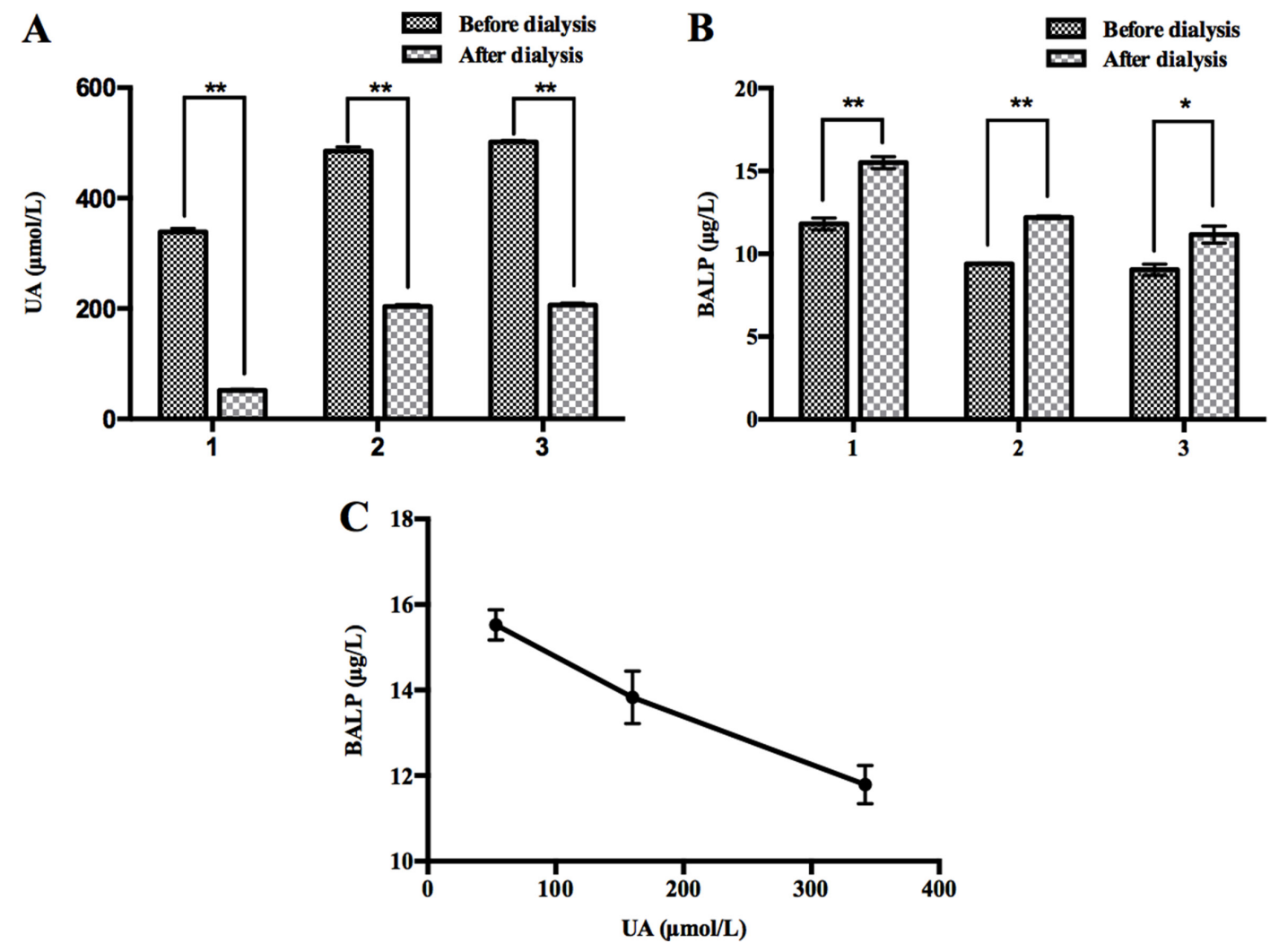

Figure 2: Partial removal of UA in vivo through renal dialysis led to increase of BALP. (A) The levels of UA after hemodialysis were lower than those before hemodialysis in three patients. Double asterisk indicates $p$ value $<0.01$. (B) The levels of BALP after hemodialysis were higher than those before hemodialysis in three patients. Double asterisk indicates $p$ value $<0.01$, and an asterisk indicates $p$ value $<0.05$. (C) Negative correlation between the concentrations of UA and BALP before, mid and after hemodialysis in No. 1 patient $(\mathrm{R}=-0.995)$. 
in BALP standard samples or the patient's serum sample (Figure 3A, 3B). Therefore, we demonstrated that high UA concentrations did not affect BALP test by interference detection method.

\section{UA suppressed BALP gene expression through inhibition of its promoter activity}

To examine whether high UA concentrations affected the expression of BALP gene, the mRNA levels of BALP were first determined in human osteosarcoma cell line (Saos-2) after treatment with a variety of doses of UA. The results showed that UA treatment decreased the mRNA levels of BALP in dose- and time-dependent manners (Figure 4A-4D). Then, we detected the protein levels of BALP in the supernatant of Saos-2 cells after treated with $200 \mu \mathrm{M}$ and $400 \mu \mathrm{M}$ UA for $12 \mathrm{~h}$, respectively (Figure 4E). The results indicated that UA treatment also reduced the protein levels of BALP in a dose-dependent manner. To reveal the mechanism, we further checked if high UA concentrations affected BALP promoter activity. We found that BALP promoter activities decreased in HEK293 cells by $27 \%$ and $71 \%$ after treatment with $200 \mu \mathrm{M}$ and $400 \mu \mathrm{M}$ UA, respectively (Figure 4F). These results suggested that high UA concentrations suppressed BALP gene expression through inhibition of its promoter activity.

\section{DISCUSSION}

Uric acid, a metabolic end-product of purine nucleotides, is considered closely related to many kinds of diseases, such as metabolic syndrome, kidney

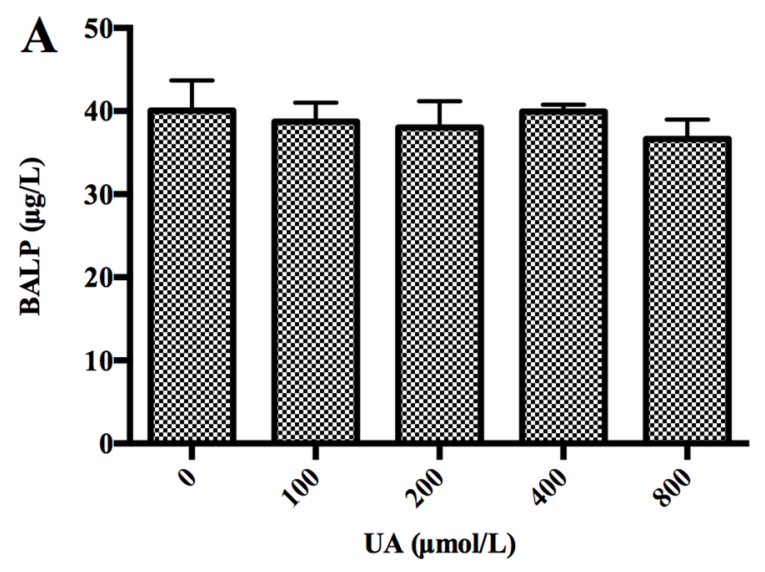

disease, hypertension and cardiovascular disorders [39-43]. As an antioxidant, high UA can decease the production of intracellular ROS and lower the value for glucose as determined by "GOD-Perid" method $[44,45]$. Several studies reported that high UA suppresses osteoclastogenesis, affects serum 1,25-(OH)2D3 levels by regulating $1 \alpha$-hydroxylase activity, and is related to low bone resorption markers [46, 47]. Recently, we reported that high UA concentrations could falsely decrease TRACP 5b, a marker of bone resorption, levels by detection method interference [38]. Here, we checked the effect of high UA exposure on BALP, one of the most commonly used bone metabolism markers, and disclosed its mechanism.

In this study, we first evaluated the differences between a total of 91 patients with high concentrations of UA and 91 healthy subjects. The results showed the average BALP level of the high-UA individuals was significantly lower than the healthy subjects. Meanwhile, we showed that lower UA concentration resulted in increase of the BALP in patients undergoing hemodialysis through renal dialysis. These data suggested that BALP was negatively affected by high UA concentrations, just as TRACP 5b. However, we confirmed that high UA concentrations did not interfere with BALP immunoassay, which was different from TRACP 5b. To disclose how high UA concentrations negatively affected the BALP levels, we detected the mRNA and protein levels of BALP in Saos-2 treated with UA or not. The results showed that high UA concentrations suppressed the mRNA and protein expression of the BALP. Recent researches have shown UA can regulate target genes expression by some different

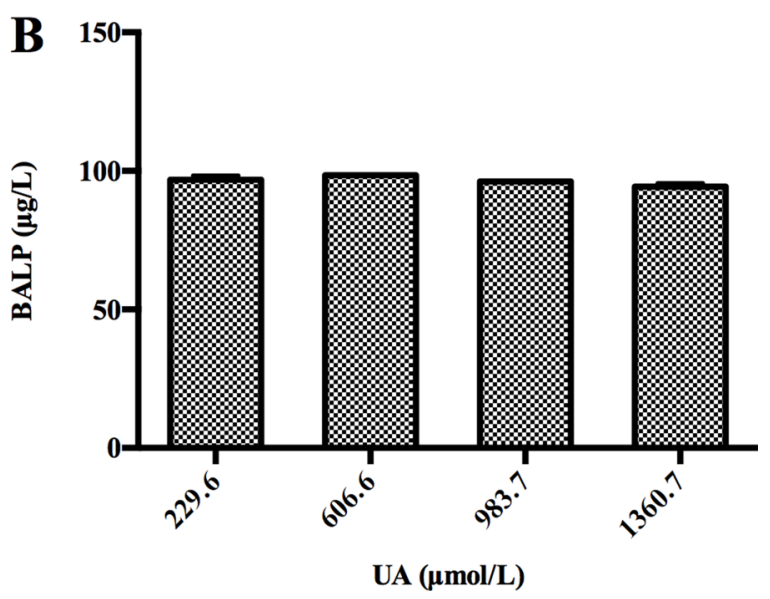

Figure 3: High concentrations of UA did not interfere with BALP level in vitro. (A) High concentrations of UA did not interfere with BALP level of BALP standard samples. A BALP standard sample was divided into 5 aliquots. Serial dilutions of UA (250, 500, 1000 and $2000 \mu \mathrm{M}$ ) were prepared from UA standard subjects. The 4 aliquots were then spiked at 3:2 with each UA solution. This generated 4 different test samples with the same BALP level, whose final UA concentrations ranged from 100 to $800 \mu \mathrm{M}$. An aliquot containing DDW instead of UA served as a blank. The average BALP concentration was marked with error bars representing standard deviations of three independent experiments. (B) High concentrations of UA did not interfere with BALP level of a serum sample from one patient with confirmed bone metastasis. A UA standard sample was spiked with a serum sample from one patient with confirmed bone metastasis (UA: $229.6 \mu \mathrm{M}$, BALP: $96.8 \mu \mathrm{g} / \mathrm{L}$ ) at 0:10, 1:9, 2:8 and 3:7, respectively. This generated 4 pools whose final UA concentrations were 229.6, 606.6, 983.7 and $1360.7 \mu \mathrm{M}$. The average corrected (multiplied by the dilution) BALP concentrations were marked with error bars representing standard deviations of three independent experiments. 
A

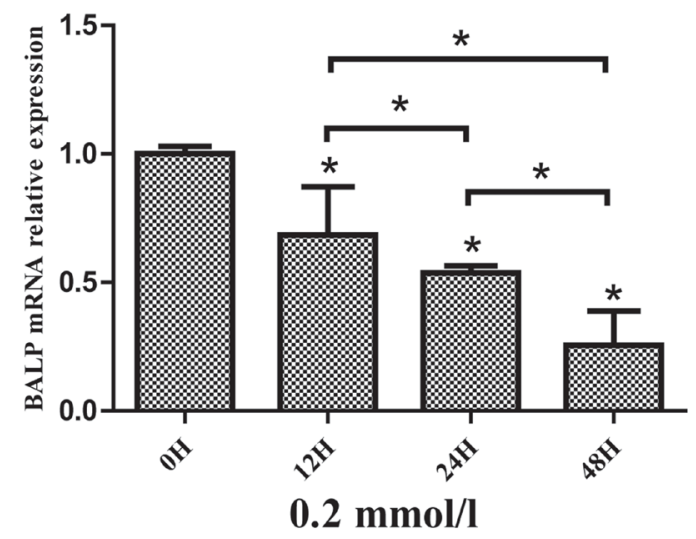

C

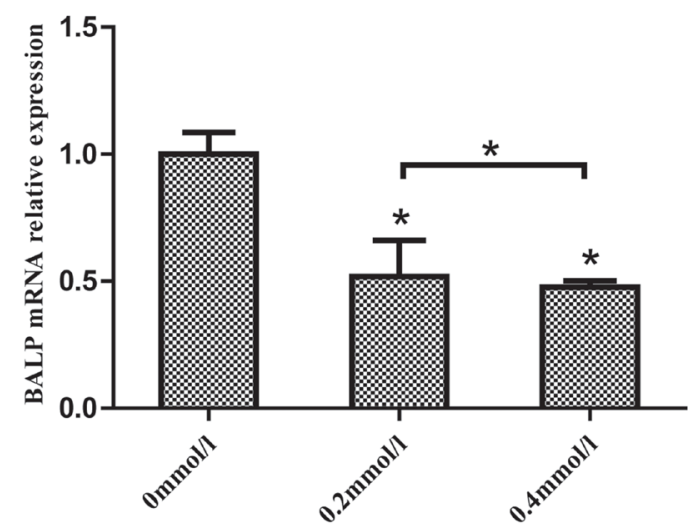

$12 \mathrm{H}$

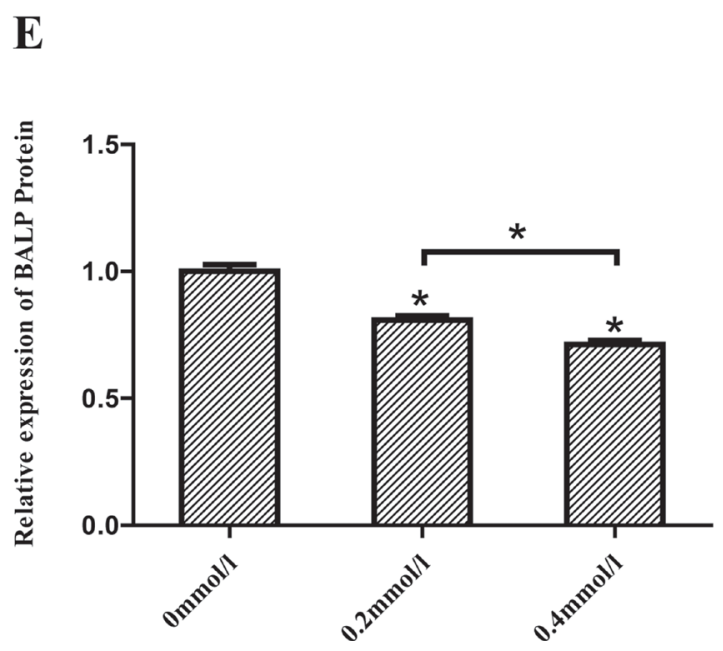

B

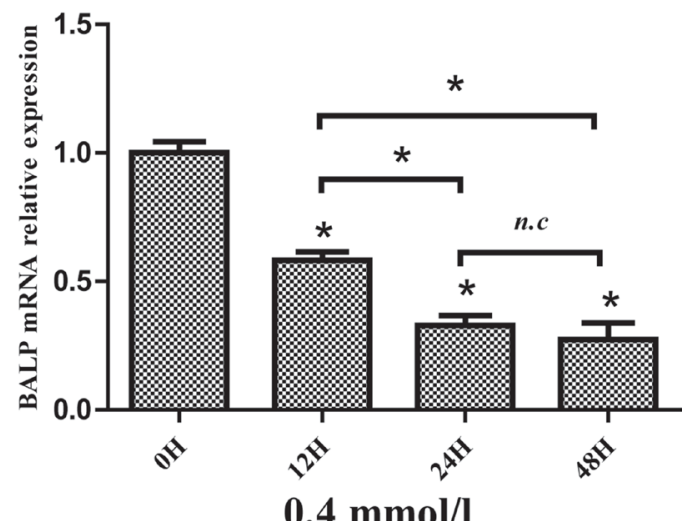

D

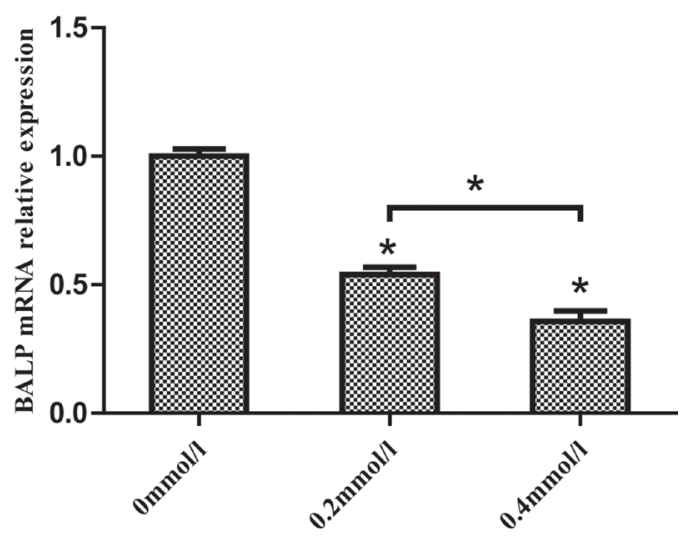

$24 \mathrm{H}$

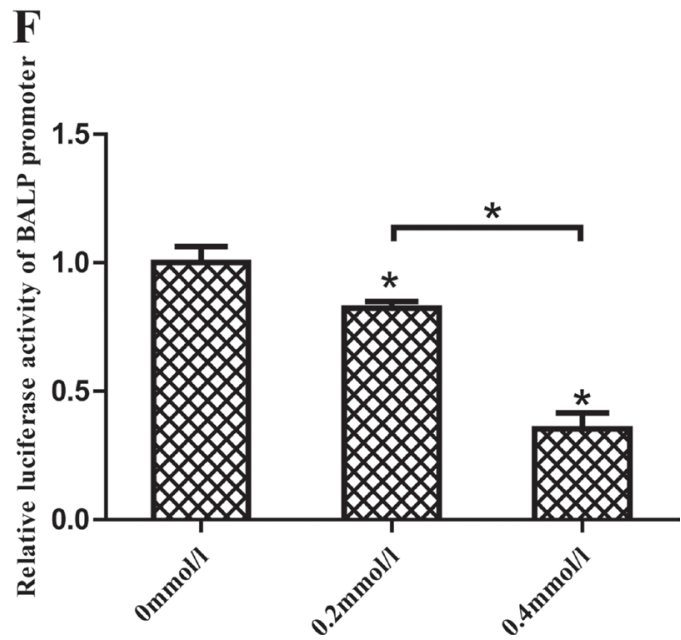

Figure 4: Uric acid suppressed BALP expression in Saos-2 cells. (A, B, C, D) Human osteoblast-like cells (Saos-2) were vaccinated in 6-well plates and incubated with $0,0.2$ or $0.4 \mathrm{mmol} / \mathrm{L}$ Uric acid. Cells were harvested after 12,24 or 48 hours and the mRNA levels of BALP were measured by qRT-PCR. Data were analyzed using the 2- $\Delta \Delta \mathrm{Cq}$ method and normalized to GAPDH. Data are represented as mean $\pm \mathrm{SD}$ of three independent experiments $\left({ }^{*} p\right.$ value $\left.<0.05\right)$. (E) Saos-2 cells were vaccinated in 6-well plates and incubated with different concentrations of UA. The supernatants were collected and the concentrations of BALP were measured. Data are represented as mean $\pm \mathrm{SD}$ of three independent experiments $(* p$ value $<0.05)$. (F) pGL3-BALP plasmids were transfected into HEK293 cells with pRL-TK using Lipofectamine 2000. After 6 hours, different concentrations $(0,0.2$ or $0.4 \mathrm{mmol} / \mathrm{L})$ of UA were added into the mediums. Luciferase activities were measured and the levels of firefly luciferase activities were normalized to the Renilla luciferase activity. Each bar represented the mean $\pm \mathrm{SD}$ of three independent experiments $\left({ }^{*} p\right.$ value $\left.<0.05\right)$. 
ways. UA induces ET-1 gene expression by the activation of ERK pathway via ROS generation [48]. UA stimulates KHK expression by binding to a specific sequence within its promoter [49]. High UA increases KLF2 expression by miR-92a downregulation [50]. Here, we confirmed that the effect of high UA on the BALP expression was through inhibition of its promoter activity.

As we know, BALP was widely used serological marker in the detection of bone metabolism. Many studies used BALP to assess bone growth and the extent of bone metastasis [51-56]. However, we did not find that UA status of the patients in these studies was considered. Tumor could promote hyperuricemia through tumor related cell death, due to tumor treatments [57]. Therefore, the reliability of previous research results based on BALP without considering serum UA status of patients needs further confirmation. Our results suggested physicians to think about serum UA status of patients with advanced cancer including lung cancer, breast cancer and prostate cancer to avoid misdiagnosis when BALP was used to diagnose or assess the extent of bone metastases.

Although we have made clear that high UA concentrations negatively affected TRACP and BALP levels, two widely used bone metabolic markers, we do not know whether other bone metabolism markers such as OC, NTX and CTX are affected by high UA concentrations. We will further disclose whether serum UA status have effects on the level of other bone metabolic markers in our future work to decrease the misdiagnosis rate of bone metabolism.

\section{MATERIALS AND METHODS}

\section{Serum sampling}

This study was approved by the Ethics Committee of the First Affiliated Hospital of Nanjing Medical University. All samples were collected from August 2014 to February 2016. Patients with cancer, hepatitis, renal dysfunction and inflammatory disease were excluded from serum collection. A total of 91 patients, including 25 women and 66 men (median age, 41 yr; range, 22-88 yrs) formed the study group. Additionally, 91 healthy subjects were sampled as the control group, including 25 women and 66 men (median age, 42 yr; range, 22-89 yrs).

\section{Data collection}

The ALT, AST, Glu, UREA, CREA and UA quantitation were analyzed using an Olympus AU5400 automatic chemical analyzer and commercial kits (Olympus, Japan) according to the instruction manual. WBC and NEU \% were counted by the Sysmex XE-2100 hematology analyzer (Sysmex, Kobe, Japan). The levels of CEA and AFP were measured by electrochemiluminescence immunoassay (ECLIA) on an Elecsys E 602 (Roche Diagnostics, Basel, Switzerland). Serum BALP was detected by using Unicel DxI 800 (Beckman Coulter, USA) device via the chemiluminescence enzyme immunometric method.

\section{UA interference experiment}

(1) A known concentration of BALP standard sample was divided into 5 aliquots. Serial dilutions of UA (250, 500,1000 and $2000 \mu \mathrm{M}$ ) were prepared from UA standard subject. The 4 aliquots were then spiked at 3:2 with each UA solution. This generated 4 distinct test samples with the same BALP concentration, final UA concentrations ranging from 100 to $800 \mu \mathrm{M}$. An aliquot containing double distilled water (DDW) instead of UA served as a blank. Then measured the BALP concentrations of each aliquot. (2) A UA standard sample was spiked with a serum sample from one patient with confirmed bone metastasis (UA: $229.6 \mu \mathrm{M}$, BALP: $96.8 \mu \mathrm{g} / \mathrm{L}$ ) at 0:10, 1:9, 2:8 and $3: 7$, respectively. This generated 4 pools whose final UA concentrations were 229.6, 606.6, 983.7 and $1360.7 \mu \mathrm{M}$. Then measured and corrected (multiplied by the dilution) BALP concentrations of each aliquot.

\section{Cell culture}

The human osteoblast-like cells (Saos-2) and human embryonic kidney 293 cells (HEK293) were obtained from ATCC and maintained in DMEM (Gibco, USA) supplemented with $10 \%$ fetal bovine serum (Gibco, USA) with $1 \%$ penicillin streptomycin, at $37^{\circ} \mathrm{C}$ in $5 \% \mathrm{CO}_{2}$, harvested by trypsinization, and subcultured twice weekly.

\section{Quantitative real-time PCR (qRT-PCR)}

Saos-2 cells were seeded at a density of 200,000 cells/well in 6-well dishes. Cells were grown in DMEM with $10 \% \mathrm{FBS}$, and then 24 hour later incubated with $0,0.2,0.4 \mathrm{mmol} / \mathrm{L}$ UA (Sigma-Aldrich, USA) for $0,12,24$ or $48 \mathrm{~h}$. Total RNA of cells was extracted with Trizol reagent (Life technologies, UK) according to manufacturer's instructions. cDNA was transcribed from total RNA using PrimeScript ${ }^{\mathrm{TM}} \mathrm{RT}$ Master Mix (Perfect Real Time) (TAKARA, JAPAN). The mRNA level of BALP and GAPDH were quantified by real timePCR using SYBR ${ }^{\circledR}$ Premix EX Taq ${ }^{\mathrm{TM}}$ (Tli RNaseH Plus) (TAKARA, JAPAN) in ABI 7300 real-time PCR system (Applied Biosystems Inc.). The forward and reverse primer sequences were designed using Olige 7 software and listed in Table 2. The GAPDH gene was used as an internal standard. The specificity of amplification was assessed by melting curve analysis for each sample. The $\Delta \Delta \mathrm{Ct}$ method was used to transform $\mathrm{Ct}$ values into relative quantities (mean \pm standard deviation). Changes were expressed as a percentage of the controls. 


\section{Table 2: Sequences of oligonucleotides used to clone BALP gene promoter and qRT-PCR amplifications}

\begin{tabular}{|c|c|c|}
\hline \multirow[b]{2}{*}{ Names } & \multicolumn{2}{|c|}{ Primer sequence $\left(5^{\prime}-3^{\prime}\right)$} \\
\hline & Forward & Reverse \\
\hline pGL3-BALP & 5' GGGGTACCGTGCAGAGTCAGAGGTGCACGT 3' & 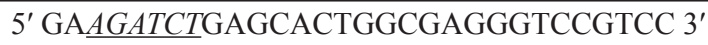 \\
\hline GAPDH & TGCACCACCAACTGCTTAGC & GGCATGGACTGTGGTCATGAG \\
\hline BALP & GGACCCTCGCCAGTGCT & GTGCACCCCAAGACCTGC \\
\hline
\end{tabular}

Primers named pGL3-BALP for cloning promoter of BALP gene: Kpn I restriction site (underlined and italics) and protective bases were introduced to the $5^{\prime}$ end of the forward primers, and $B g l$ II restriction site (underlined and italics) and protective bases were added to the 5 ' end of the reverse primers. Primers named as GAPDH and BALP for qRT-PCR.

\section{Generation of report plasmid constructs}

A $5^{\prime}$ flanking upstream (including promoter region) of BALP (NM 000478.5) (from -473 to $+154 \mathrm{nt}$ relative to transcription start site) was amplified from genomic DNA by PrimeSTAR ${ }^{\circledR}$ HS DNA Polymerase (TAKARA, JAPAN) according to manufacturer's protocol. The forward and reverse primers were designed using Olige 7 software and listed in Table 2. The PCR products were digested with Kpn I and Bgl II (Thermo Fisher Scientific, USA) and then subcloned to a promoter-less vector pGL3-Basic restrictively digested with Kpn I and $B g l I I$. The recombinant plasmids were tested and sequenced, and the positive cloned plasmid was named as pGL3-BALP.

\section{Transient transfections and luciferase assays}

Transient transfections were carried out in HEK293 cells using Lipofectamine2000 (Invitrogen, USA) according to the manufacturer's suggestion. Cells were vaccinated in a 48-well culture plates and when the cells had grown to $70-80 \%$ before transfection. For luciferase assays, $200 \mathrm{ng}$ of pGL3-BALP plasmid was cotransfected into HEK293 cells with 2 ng of control pRL-TK plasmids as an internal control. After 6 hours, cells were incubated with different doses $(0,0.2$, $0.4 \mathrm{mmol} / \mathrm{L}$ ) of UA, respectively. After 24 hours, cells were harvested and luciferase assays were measured with the Dual Reporter assay system (Promega, USA) using FB12 luminometer (Berthold, Germany). The relative luciferase activities (RLA) were calculated by normalizing the fluorescence luciferase with internal standard Renilla luciferase.

\section{Statistical analysis}

The statistical software package SPSS17.0 (SPSS Inc, Chicago, USA) was used for data analysis. Data were presented as means $\pm \mathrm{SD}$ and represented at least three independent experiments. Two-tailed $t$-tests were used for significance testing between groups of continuous data. For all statistical comparisons, a $p$ value $<0.05$ was considered statistically significant.

\section{Ethical standards and patient consent}

Ethical clearance for this study was obtained from the Ethics Committee at the First Affiliated Hospital of Nanjing Medical University. Because all the samples used in this study were collected from clinical residual specimen, written informed content from each patient was waived. This study was conducted in accordance with the Declaration Helsinki.

\section{Author contributions}

Performed the experiments: Z.-Q.W., X.-T.C. and Y.-Y.X. Analyzed the data: Z.-Q.W., X.-T.C., Y.-Y.X., M.J.T., H.-Y.C., G.-P.Z. and H.-G.X. Contributed reagents/ materials/ analysis tools: Z.-Q.W., X.-T.C. and H.-G.X. Conceived and designed the experiments and Wrote the paper: H.-G.X.

\section{CONFLICTS OF INTEREST}

The authors declare no competing financial interests.

\section{FUNDING}

This work was supported by the National Natural Science Foundation of China (81302531), Natural Science Foundation of Jiangsu Province of China (BK20131018), the Talents Planning of Six Summit Fields of Jiangsu Province (2013-WSN-037), the National Key Clinical Department of Laboratory Medicine of China in Nanjing, Key laboratory for Laboratory Medicine of Jiangsu Province (ZDXKB2016005) and by the Priority Academic Program Development of Jiangsu Higher Education Institutions.

\section{REFERENCES}

1. Wu YY, Janckila AJ, $\mathrm{Ku} \mathrm{CH}, \mathrm{Yu} \mathrm{CP}, \mathrm{Yu}$ JC, Lee $\mathrm{SH}$, Liu HY, Yam LT, Chao TY. Serum tartrate-resistant acid phosphatase $5 \mathrm{~b}$ activity as a prognostic marker of survival in breast cancer with bone metastasis. BMC Cancer. 2010; 10:158-9. https://doi.org/10.1186/1471-2407-10-158. 
2. Wu Z, Wei D, Gao W, Xu Y, Hu Z, Ma Z, Gao C, Zhu X, Li Q. TPO-Induced Metabolic Reprogramming Drives Liver Metastasis of Colorectal Cancer CD110+ Tumor- Initiating Cells. Stem Cell. 2015; 17:47-59. https://doi.org/10.1016/j. stem.2015.05.016.

3. Johansson JE, Andrén O, Andersson SO, Dickman PW, Holmberg L, Magnuson A, Adami HO. Natural history of early, localized prostate cancer. JAMA. 2004; 291:2713-9. https://doi.org/10.1001/jama.291.22.2713.

4. Mundy GR. Metastasis to bone: causes, consequences and therapeutic opportunities. Nature Reviews Cancer. 2002; 2:584-593. https://doi.org/10.1038/nrc867.

5. Yin JJ, Pollock CB, Kelly K. Mechanisms of cancer metastasis to the bone. Cell Research. 2005; 15:57-62. https://doi.org/10.1038/sj.cr.7290266.

6. Zhang Y, Ma B, Fan Q. Mechanisms of breast cancer bone metastasis. Cancer Letters. 2010; 292:1-7. https://doi. org/10.1016/j.canlet.2009.11.003.

7. Chen YC, Sosnoski DM, Mastro AM. Breast cancer metastasis to the bone: mechanisms of bone loss. Breast Cancer Res. 2010; 12:215. https://doi.org/10.1186/bcr2781.

8. Ye L, Kynaston HG, Jiang WG. Bone metastasis in prostate cancer: molecular and cellular mechanisms (Review). Int J Mol Med. 2007; 20:103-11.

9. Cher ML. Mechanisms governing bone metastasis in prostate cancer. Curr Opin Urol. 2001; 11:483-8.

10. Bilgin E, Yasasever V, Soydinc HO, Yasasever CT, Ozturk N, Duranyildiz D. Markers of bone metastases in breast and lung cancers. Asian Pac J Cancer Prev. 2012; 13:4331-4.

11. Chua S, Gnanasegaran G, Cook GJR. Miscellaneous cancers (lung, thyroid, renal cancer, myeloma, and neuroendocrine tumors): role of SPECT and PET in imaging bone metastases. Semin Nucl Med. 2009; 39:416-30. https://doi. org/10.1053/j.semnuclmed.2009.07.002.

12. Atasever T, Gündoğdu C, Vural G, Kapucu LO, Karalezli A, Unlü M. Evaluation of pentavalent Tc-99m DMSA scintigraphy in small cell and nonsmall cell lung cancers. Nuklearmedizin. 1997; 36:223-7.

13. Almeida AG. Subclinical cardiotoxicity in cancer therapy: The impact of early detection. Rev Port Cardiol. 2017; 36:17-9. https://doi.org/10.1016/j.repc.2016.10.003.

14. Bagaria M, Shields E, Bakkum-Gamez JN. Novel approaches to early detection of endometrial cancer. Curr Opin Obstet Gynecol. 2017; 29:40-6. https://doi. org/10.1097/GCO.0000000000000332.

15. Wadia SK, Shah TG, Hedstrom G, Kovach JA, Tandon R. Early detection of right ventricular dysfunction using transthoracic echocardiography in ARDS: a more objective approach. Echocardiography. 2016; 33:1874-9. https://doi. org/10.1111/echo.13350.

16. Damian A, Lago G, Rossi S, Alonso O, Engler H. Early detection of bone metastasis in small cell neuroendocrine carcinoma of the cervix by $68 \mathrm{Ga}-\mathrm{DOTATATE} \mathrm{PET} / \mathrm{CT}$ imaging. Clin Nucl Med. 2017; 42:216-217. https://doi. org/10.1097/RLU.0000000000001498.

17. O'Sullivan JM, Cook GJR. A review of the efficacy of bone scanning in prostate and breast cancer. Q J Nucl Med. 2002; 46:152-9.

18. Gutzeit A, Doert A, Froehlich JM, Eckhardt BP, Meili A, Scherr P, Schmid DT, Graf N, von Weymarn CA, Willemse EM, Binkert CA. Comparison of diffusion-weighted whole body MRI and skeletal scintigraphy for the detection of bone metastases in patients with prostate or breast carcinoma. Skeletal Radiol. 2010; 39:333-43. https://doi. org/10.1007/s00256-009-0789-4.

19. Prior JO, Barghouth G, Delaloye JF, Leyvraz S, Bischof Delaloye A. The value of bone marrow scintigraphy using $99 \mathrm{mTc}$ monoclonal antigranulocyte antibodies in complement to bone scintigraphy in detecting bone metastases from primary breast cancer. Nucl Med Commun. 2003; 24:29-36. https://doi.org/10.1097/01. mnm.0000051629.18733.85.

20. Palmedo H, Marx C, Ebert A, Kreft B, Ko Y, Türler A, Vorreuther R, Göhring U, Schild HH, Gerhardt T, Pöge U, Ezziddin S, Biersack HJ, et al. Whole-body SPECT/CT for bone scintigraphy: diagnostic value and effect on patient management in oncological patients. Eur J Nucl Med Mol Imaging. 2014; 41:59-67. https://doi.org/10.1007/s00259013-2532-6.

21. Poulsen MH, Petersen H, Høilund-Carlsen PF, Jakobsen JS, Gerke O, Karstoft J, Steffansen SI, Walter S. Spine metastases in prostate cancer: comparison of technetium99m-MDP whole-body bone scintigraphy, [(18) F]choline positron emission tomography(PET)/computed tomography (CT) and [(18) F]NaF PET/CT. BJU Int. 2014; 114:818-23. https://doi.org/10.1111/bju.12599.

22. Cook GJ, Venkitaraman R, Sohaib AS, Lewington VJ, Chua SC, Huddart RA, Parker CC, Dearnaley DD, Horwich A. The diagnostic utility of the flare phenomenon on bone scintigraphy in staging prostate cancer.Eur J Nucl Med Mol Imaging. 2011; 38:7-13. https://doi.org/10.1007/s00259010-1576-0.

23. Balliu E, Boada M, Peláez I, Vilanova JC, Barceló-Vidal C, Rubio A, Galofré P, Castro A, Pedraza S. Comparative study of whole-body MRI and bone scintigraphy for the detection of bone metastases. Clin Radiol. 2010; 65:989-96. https:// doi.org/10.1016/j.crad.2010.07.002.

24. Coleman R, Brown J, Terpos E, Lipton A, Smith MR, Cook R, Major P. Bone markers and their prognostic value in metastatic bone disease: clinical evidence and future directions. Cancer Treatment Reviews. 2008; 34:629-39. https://doi.org/10.1016/j.ctrv.2008.05.001.

25. Huang Q, Ouyang X. Biochemical-markers for the diagnosis of bone metastasis: a clinical review. Cancer Epidemiol. 2012; 36:94-8. https://doi.org/10.1016/j.canep.2011.02.001.

26. Jung K, Lein M. Bone turnover markers in serum and urine as diagnostic, prognostic and monitoring biomarkers of bone 
metastasis. Biochim Biophys Acta. 2014; 1846:425-38. https://doi.org/10.1016/j.bbcan.2014.09.001.

27. Wang Z, Lu Y, Qiao D, Wen X, Zhao H, Yao Y. Diagnostic and prognostic validity of serum bone turnover markers in bone metastatic non-small cell lung cancer patients. J Bone Oncol. 2015; 4:85-91. https://doi.org/10.1016/j. jbo.2015.09.003.

28. Sarvari BK, Sankara Mahadev D, Rupa S, Mastan SA. Detection of Bone Metastases in Breast Cancer (BC) Patients by Serum Tartrate-Resistant Acid Phosphatase 5b (TRACP 5b), a Bone Resorption Marker and Serum Alkaline Phosphatase (ALP), a Bone Formation Marker, in Lieu of Whole Body Skeletal Scintigraphy with Technetium99m MDP. Indian J Clin Biochem. 2015; 30: 66-71. https://doi.org/10.1007/s12291-013-0399-8.

29. Galliera E, Luzzati A, Perrucchini G, Gagliano F, Colloredo Mels L, Banfi G, Corsi Romanelli MM, Drago L. Bone formation and resorption markers as diagnostic tools for bone metastases evaluation. Int J Biol Markers. 2012; 27:e395-9. https://doi.org/10.5301/JBM.2012.9579.

30. Samoszuk M, Leuther M, Hoyle N. Role of serum P1NP measurement for monitoring treatment response in osteoporosis. Biomark Med. 2008; 2:495-508. https://doi. org/10.2217/17520363.2.5.495.

31. Oremek G, Sauer-Eppel H, Klepzig M. Total procollagen type 1 amino-terminal propeptide (total P1NP) as a bone metastasis marker in gynecological carcinomas. Anticancer Res. 2007; 27:1961-2.

32. Wei RJ, Li TY, Yang XC, Jia N, Yang XL, Song HB. Serum levels of PSA, ALP, ICTP, and BSP in prostate cancer patients and the significance of ROC curve in the diagnosis of prostate cancer bone metastases. Genet Mol Res. 2016; 15. https://doi.org/10.4238/gmr.15027707.

33. Wade-Gueye NM, Boudiffa M, Vanden-Bossche A, Laroche $\mathrm{N}$, Aubin JE, Vico L, Lafage-Proust MH, Malaval L. Absence of bone sialoprotein (BSP) impairs primary bone formation and resorption: the marrow ablation model under PTH challenge. Bone. 2012; 50:1064-73.

34. Chen J, Younusi A, Cao L, Xu L, Zhou Y, Zhen T, Song $X$. Serum levels of NTx and TRACP5b in giant cell tumor of bone and its clinical implications. Clin Lab. 2015; 61:1077-81.

35. Wiwanitkit V. NTx as marker for bone resorption in CKD. Eur J Intern Med. 2011; 22:123. https://doi.org/10.1016/j. ejim.2010.07.007.

36. Tanishi N, Yamagiwa H, Hayami T, Mera H, Koga Y, Omori G, Endo N. Usefulness of urinary CTX-II and NTX-I in evaluating radiological knee osteoarthritis: the Matsudai knee osteoarthritis survey. J Orthop Sci. 2014; 19:429-436. https://doi.org/10.1007/s00776-014-0535-1.

37. Tanishi N, Yamagiwa H, Hayami T, Mera H, Koga Y, Omori G, Endo N. Relationship between radiological knee osteoarthritis and biochemical markers of cartilage and bone degradation (urine CTX-II and NTX-I): the Matsudai
Knee Osteoarthritis Survey. J Bone Miner Metab. 2009; 27:605-12. https://doi.org/10.1007/s00774-009-0077-3.

38. Wu ZQ, Zhang Y, Xie E, Song WJ, Yang RX, Yan CJ, Zhang BF, Xu HG. High uric acid (UA) negatively affects serum tartrate-resistant acid phosphatase 5b (TRACP 5b) immunoassay. PloS one. 2016; 11:e0147554. https://doi. org/10.1371/journal.pone.0147554.

39. Jin M, Yang F, Yang I, Yin Y, Luo JJ, Wang H, Yang XF. Uric acid, hyperuricemia and vascular diseases. Front Biosci (Landmark Ed). 2012; 17:656-69.

40. Holme I, Aastveit AH, Hammar N, Jungner I, Walldius G. Uric acid and risk of myocardial infarction, stroke and congestive heart failure in 417,734 men and women in the Apolipoprotein MOrtality RISk study (AMORIS). J Intern Med. 2009; 266:558-70. https://doi.org/10.1111/j.13652796.2009.02133.x.

41. Leow MK. Uric acid and cardiovascular risk. N Engl J Med. 2009; 360:538-9- author reply 540-1. https://doi. org/10.1056/NEJMc082360.

42. Maiolino G, Pagnin E, Plebani M, Davis PA, Calò LA. Uric acid and cardiovascular-renal disease risk. Insights from a human model opposite to hypertension. Int J Cardiol. 2016; 212:18-9. https://doi.org/10.1016/j.ijcard.2016.03.036.

43. Choi HK, Ford ES. Prevalence of the metabolic syndrome in individuals with hyperuricemia. Am J Med. 2007; 120:442-7. https://doi.org/10.1016/j.amjmed.2006.06.040.

44. Sautin YY, Johnson RJ. Uric acid: the oxidant-antioxidant paradox, Nucleosides Nucleotides Nucleic Acids. 2008; 27:608-19. https://doi.org/10.1080/15257770802138558.

45. Chinh NH. Mechanism of interference by uric acid in the glucose oxidase-peroxidase method for serum glucose. Clinical Chemistry. 1974; 20:499-501.

46. Takahashi S, Yamamoto T, Moriwaki Y, Tsutsumi Z, Yamakita J, Higashino K. Decreased serum concentrations of 1,25(OH)2-vitamin D3 in patients with gout. Metab Clin Exp. 1998; 47:336-8.

47. Ahn SH, Lee SH, Kim BJ, Lim KH, Bae SJ, Kim EH, Kim HK, Choe JW, Koh JM, Kim GS. Higher serum uric acid is associated with higher bone mass, lower bone turnover, and lower prevalence of vertebral fracture in healthy postmenopausal women. Osteoporos Int. 2013; 24:2961-70. https://doi.org/10.1007/s00198-013-2377-7.

48. Cheng TH, Lin JW, Chao HH, Chen YL, Chen CH, Chan $\mathrm{P}$, Liu JC. Uric acid activates extracellular signal-regulated kinases and thereafter endothelin-1 expression in rat cardiac fibroblasts. Int J Cardiol. 2010; 139:42-9. https://doi. org/10.1016/j.ijcard.2008.09.004.

49. Lanaspa MA, Sanchez-Lozada LG, Cicerchi C, Li N, Roncal-Jimenez CA, Ishimoto T, Le M, Garcia GE, Thomas JB, Rivard CJ, Andres-Hernando A, Hunter B, Schreiner $\mathrm{G}$, et al. Uric acid stimulates fructokinase and accelerates fructose metabolism in the development of fatty liver. PloS one. 2012; 7:e47948. https://doi.org/10.1371/journal. pone. 0047948 . 
50. Yu S, Hong Q, Wang Y, Hou K, Wang L, Zhang Y, Fu B, Zhou Y, Zheng W, Chen X, Wu D. High concentrations of uric acid inhibit angiogenesis via regulation of the Krüppellike factor 2-vascular endothelial growth factor-A axis by miR-92a. Circ J. 2015; 79:2487-98. https://doi.org/10.1253/ circj.CJ-15-0283.

51. Parker C, O'Bryan-Tear CG, Bolstad B, Lokna A, Nilsson S. Alkaline phosphatase (ALP) normalization and overall survival in patients with bone metastases from castrationresistant prostate cancer (CRPC) treated with radium-223. J Clin Oncol. 2011; 29:a4620.

52. Wolff JM, Ittel T, Borchers H, Brauers A, Jakse G. Efficacy of skeletal alkaline phosphatase and prostate-specific antigen in the diagnosis of bone metastasis in cancer of the prostate. Urol. Int. 1998; 61:12-6.

53. Lorente JA, Morote J. Behavior of bone alkaline phosphatase (BAP) determined with immunoradiometric assay in metastatic prostate cancer. Int J Biol Markers. 1994; 9:145.
54. Cooper EH, Whelan P, Purves D. Bone alkaline phosphatase and prostate-specific antigen in the monitoring of prostate cancer. Prostate. 1994; 25:236-42.

55. Ramaswamy G, Rao VR, Krishnamoorthy L, Ramesh G, Gomathy R, Renukadevi D. Serum levels of bone alkaline phosphatase in breast and prostate cancers with bone metastasis. Indian J Clin Biochem. 2000; 15:110-3. https:// doi.org/10.1007/BF02883737.

56. Schindler F, Lajolo PP, Pinczowski H, Fonseca FL, Barbieri A, Massonetto LH, Katto FT, Del Giglio A. Bone and total alkaline phosphatase for screening skeletal metastasis in patients with solid tumours. Eur J Cancer Care (Engl). 2008; 17:152-6. https://doi.org/10.1111/j.13652354.2007.00826.x.

57. Fini MA, Elias A, Johnson RJ, Wright RM. Contribution of uric acid to cancer risk, recurrence, and mortality. Clin Transl Med. 2012; 1:16. https://doi.org/10.1186/2001-1326$1-16$. 